\title{
A clinical study of morphological patterns of cutaneous adverse drug reaction and its causality assessment in tertiary care hospital of central India
}

\author{
Tanaji R. Shende, Riyaz A. Siddqui
}

Department of Pharmacology, NKPSIMS and RC and LMH, Digdoh Hingna Road, Nagpur, Maharashtra, India

Received: 07 July 2020

Accepted: 18 August 2020

*Correspondence:

Dr. Riyaz A. Siddiqui,

Email: riyaz19752008@gmail.com

Copyright: (C) the author(s), publisher and licensee Medip Academy. This is an open-access article distributed under the terms of the Creative Commons Attribution Non-Commercial License, which permits unrestricted non-commercial use, distribution, and reproduction in any medium, provided the original work is properly cited.

\begin{abstract}
Background: Adverse reactions to drugs are as old as drug. Cutaneous adverse drug reactions are the most common type of drug reaction. Most cutaneous adverse drug reactions are important as they are frequently the reason for discontinuation of drug therapy. Looking to this matter the study was undertaken.

Method: It was an observational study conducted at NKP Salve Institute of Medical Science \& Research Centre, Nagpur Maharashtra. A total number of 80 patients having cutaneous adverse drug reaction were evaluated. All the patients were assessed for cutaneous adverse drug reaction during the study period and the information was carefully recorded in standard Adverse drug reaction (ADR) form and Naranjo's algorithm was used for causality assessment of adverse drug reaction.

Result: The maximum study subjects were in the age group of 41-50 years (32-50\%) followed by the age group of 3140 years $(25 \%)$ followed by other age groups. In study group male to female ratio was 11.5:8.5. Majority of cutaneous adverse drug reactions comprise of fixed drug eruption which is $45 \%$. Most of the cutaneous ADR's were caused by antibiotics $(42.5 \%)$ followed by Non-steroidal anti-inflammatory drugs (NSAIDS) (20\%). The study subjects were in probable causality assessment of Naranjo's scale i.e. $82.5 \%$ followed by definite in $(12.5 \%)$ and possible $(5 \%)$.

Conclusion: The fixed drug eruption was the most common cutaneous adverse drug reaction and most of these drugs eruptions were caused by antimicrobial agents. The study provided the base line information about the prevalence of cutaneous adverse drug reaction and their morphological distribution amongst different age group, gender and the causative drug.
\end{abstract}

Keywords: Fixed drug eruption, Urticaria, Antimicrobials, NSAIDs

\section{INTRODUCTION}

Adverse reaction to drug is very common in everyday medical practice. Adverse reaction to drug as old as drug. Adverse reaction to drug is most common iatrogenic illness complication 5 to $15 \%$ of therapeutic courses. Cutaneous drug reaction is any drug reaction with a sign and symptoms of skin, its appendages (hairs, nails) or mucous membrane appearing with in a two week of medication. ${ }^{1}$ These are the most common type of adverse drug reaction (ADR). ${ }^{2}$ The main drug responsible to cause drug eruption are antibiotics and Non-steroidal antiinflammatory drugs (NSAIDs). ${ }^{3}$ The most cutaneous adverse drug reactions are not associated with seriousness, morbidity but are important as they are frequently the reason for discontinuation of drug therapy. ${ }^{4}$ The diagnosis of Cutaneous ADR (CADR) will be continuing to an intellectual challenge for all physicians. ${ }^{5}$ 
Common form of CADR includes urticaria, maculopapular rash, fixed drug eruption, Steven Johnson syndrome (SJS). The diagnosis of drug reaction is basically clinical, only for certain cases further in vivo and in vitro tests are required. Since very few studies are conducted in this field the present study is undertaken to study of morphological patterns of cutaneous ADR observed in dermatology practice and evaluating causality assessment of suspected CADR.

\section{METHODS}

\section{Source of data}

The study was conducted in the department of Skin and Venereal Diseases at NKP Salve Institute of Medical Science and research center and Lata Mangeshkar Hospital, Digdoh Hingna Road, Nagpur. The outdoor patient and indoor patient with suspected drug reaction or who were referred to skin department for evaluation were considered for study. The duration of study was from December 2017 to 2019 .

\section{Method of collection of data}

A prospective observation non-randomized hospital-based study was done to record various CADR pattern.

\section{Inclusion criteria}

The following patients were included in study group: Patients with cutaneous adverse drug reaction who have documented evidence of having taken the suspected drug, patients of either sex and all age groups patients.

\section{Exclusion criteria}

The following patients were excluded from the study group: Cases associated with vaccines, over dosages, patients who were on alternative medicines. Example: homeopathy, herbal medicines, ayurvedic medicines.

\section{Study procedure}

The official approval was taken from Institutional Ethics Committee to carry out the study. A total number of 80 patients having cutaneous adverse reaction were included in the study. An informed written consent was taken from each patient. A detail history regarding drug intake, onset of symptoms, duration of reaction and morphology of eruption and associated mucosal or systemic involvement of lesion, previous allergic history was noted.

The data was filled in suspected ADR form. All the information was carefully recorded in standard ADR form. Data entered in Microsoft excel sheet and the software Epiinfo version 7.2.2 used for evaluation. Naranjo's algorithm was used for causality assessment of ADR. ${ }^{6}$

\section{RESULTS}

The Table 1 shows that among the study subjects, maximum study subject was in age group of 41-50 years i.e. $32.50 \%$ followed by $25 \%$ in age group of $31-40$ years; the male to female ratio was 11.5:8.5; the oldest patient in the study was 70 years and youngest was 11 years.

Table 1: Age and sex distribution in study patients.

\begin{tabular}{|llll|}
$\begin{array}{l}\text { Age } \\
\text { group } \\
\text { (year) }\end{array}$ & Male $(\%)$ & Female $(\%)$ & Total $(\%)$ \\
\hline $\mathbf{1 1 - 2 0}$ & $2(4.3)$ & $0(0)$ & $2(2.5)$ \\
\hline $\mathbf{2 1 - 3 0}$ & $8(17.40)$ & $4(11.76)$ & $12(15)$ \\
\hline $\mathbf{3 1 - 4 0}$ & $8(17.40)$ & $12(35.30)$ & $20(25)$ \\
\hline $\mathbf{4 1 - 5 0}$ & $16(34.81)$ & $10(29.41)$ & $26(32.50)$ \\
\hline $\mathbf{5 1 - 6 0}$ & $12(26.09)$ & $4(11.76)$ & $18(20)$ \\
\hline $\mathbf{6 1 - 7 0}$ & $0(0)$ & $4(11.76)$ & $4(5)$ \\
\hline Total & $46(100)$ & $34(100)$ & $80(100)$ \\
\hline
\end{tabular}

Table 2: Distribution of onset of reaction in study patient.

\begin{tabular}{|llll|}
\hline $\begin{array}{l}\text { On set of } \\
\text { reaction }\end{array}$ & Male $(\%)$ & Female $(\%)$ & $\begin{array}{l}\text { Total } \\
(\%)\end{array}$ \\
\hline $\begin{array}{l}\text { 24 hours } \\
\mathbf{2 4} \text { hours- } \\
\text { 1 week }\end{array}$ & $18(39.13)$ & $14(41.18)$ & $32(40)$ \\
\hline$>\mathbf{1}$ week & $8(17.40)$ & $6(17.64)$ & $\begin{array}{l}\text { (4) } \\
(14.50)\end{array}$ \\
\hline Total & $46(100)$ & $34(100)$ & $80(100)$ \\
\hline
\end{tabular}

Table 2 shows that among the study subjects the onset of reaction in majority of patients i.e. 34 (42.50\%) was between 24 hours to 1 week followed by less than 24 hours and more than 1 week in $32(40 \%)$ and $14(17.50 \%)$ respectively.

Table 3: Distribution of progression of symptoms associated symptoms and total duration of reaction among study subjects.

\begin{tabular}{|c|c|c|c|}
\hline & Male (\%) & Female (\%) & Total $(\%)$ \\
\hline \multicolumn{4}{|c|}{ Progression of symptoms } \\
\hline Sudden & $18(39.13)$ & $14(41.17)$ & $32(40)$ \\
\hline Gradual & $28(60.87)$ & $20(58.82)$ & $48(60)$ \\
\hline \multicolumn{4}{|c|}{ Associated symptoms } \\
\hline Present & $26(56.52)$ & $20(58.82)$ & $46(57.50)$ \\
\hline Absent & $20(43.47)$ & $14(41.17)$ & $34(42.50)$ \\
\hline \multicolumn{4}{|c|}{ Total duration of reaction } \\
\hline$<1$ week & $38(82.60)$ & $20(58.82)$ & $58(72.50)$ \\
\hline$>1$ week & $8(17.40)$ & $14(41.17)$ & $22(27.50)$ \\
\hline Total & $46(100)$ & $34(100)$ & $80(100)$ \\
\hline
\end{tabular}

Table 3 shows that study subject associated symptoms was seen in $57.50 \%$, gradually progression of symptoms was seen in $60 \%$ which was in majority. Table also shows that 
the total duration of reaction was less than one week in $72.50 \%$ followed by more than one week in $27.50 \%$.

Table 4: Distribution of various pattern of cutaneous ADR's among study subjects.

\begin{tabular}{|llll|}
\hline $\begin{array}{l}\text { Diagnosis } \\
\text { Angio- } \\
\text { edema }\end{array}$ & $2(4.35)$ & $2(5.88)$ & $4(5)$ \\
\hline $\begin{array}{l}\text { Fixed drug } \\
\text { eruption }\end{array}$ & $20(43.45)$ & $16(47.03)$ & $36(45)$ \\
\hline $\begin{array}{l}\text { Hyperpigm } \\
\text { entation }\end{array}$ & $4(8.7)$ & $0(0)$ & $4(5)$ \\
\hline $\begin{array}{l}\text { Maculopap } \\
\text { ular } \\
\text { eruption }\end{array}$ & $8(17.40)$ & $8(23.59)$ & $16(20)$ \\
\hline $\begin{array}{l}\text { SJ } \\
\text { Syndrome }\end{array}$ & $2(4.35)$ & $2(5.88)$ & $4(5)$ \\
\hline $\begin{array}{l}\text { Urticaria }+ \\
\text { angioedema }\end{array}$ & $2(4.35)$ & $2(5.88)$ & $4(5)$ \\
\hline Urticaria & $8(17.40)$ & $4(11.74)$ & $12(15)$ \\
\hline Total & $46(100)$ & $34(100)$ & $80(100)$ \\
\hline
\end{tabular}

Table 4 and Figure 1 shows that majority of cutaneous ADR's comprised of fixed drug eruption i.e. $45 \%$ followed by maculopapular eruption $20 \%$ urticaria $15 \%$, angioedema, hyperpigmentation, SJS, urticaria and angioedema $5 \%$.

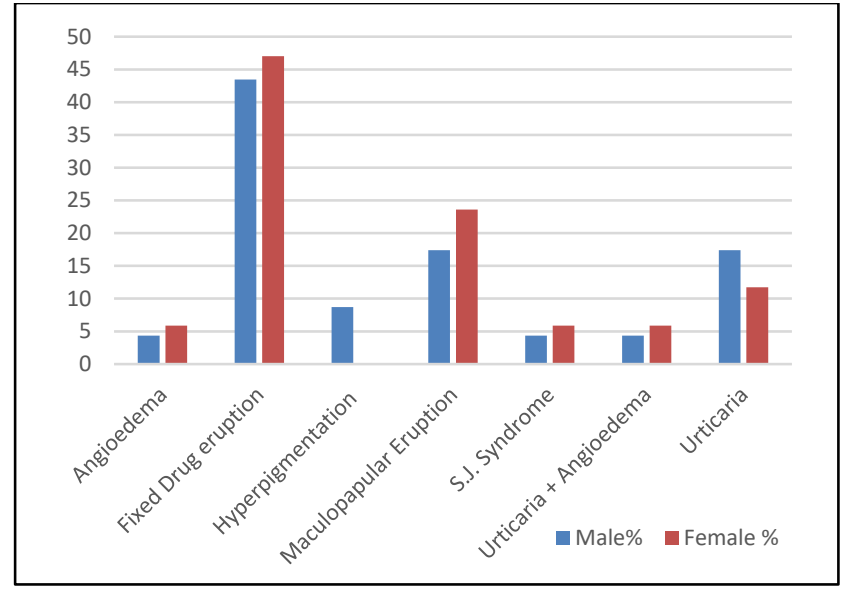

Figure 1: Distribution of various patterns of CADRS among study subjects.

Table 5: Naranjo's scale (causality assessment).

\begin{tabular}{|llll|}
$\begin{array}{l}\text { Naranjo's } \\
\text { Scale }\end{array}$ & Male $(\%)$ & Female $(\%)$ & Total $(\%)$ \\
\hline Definite & $8(17.40)$ & $2(5.88)$ & $10(12.5)$ \\
\hline Possible & $2(4.34)$ & $2(5.88)$ & $4(5)$ \\
\hline Probable & $36(78.26)$ & $30(88.44)$ & $66(82.5)$ \\
\hline Total & $46(100)$ & $34(100)$ & $80(100)$ \\
\hline
\end{tabular}

Table 6: Cutaneous ADRs and Naranjo's algorithm.

\begin{tabular}{|lllll|}
\hline Cutaneous ADR & Definite $(\%)$ & Possible $(\%)$ & Probable $(\%)$ & Total $(\%)$ \\
\hline Angioedema & $0(0)$ & $0(0)$ & $4(6.08)$ & $4(5)$ \\
\hline Fixed drug eruption & $6(60)$ & $0(0)$ & $28(42.42)$ & $34(42.5)$ \\
\hline Hyperpigmentation & $0(0)$ & $2(50)$ & $4(6.08)$ & $4(5)$ \\
\hline Maculopapular Eruption & $0(0)$ & $0(0)$ & $14(21.21)$ & $16(20)$ \\
\hline SJ Syndrome & $2(20)$ & $0(0)$ & $2(3.06)$ & $4(5)$ \\
\hline Urticaria+angioede-ma & $2(20)$ & $2(50)$ & $10(15.15)$ & $12(15)$ \\
\hline Urticaria & $0(0)$ & $4(100)$ & $4(6.08)$ & $6(7.5)$ \\
\hline Total & $10(100)$ & $66(100)$ & $80(100)$ \\
\hline
\end{tabular}

Table 7: Common incriminated drug causing CADRs.

\begin{tabular}{|c|c|c|c|}
\hline Group (\%) & Drugs & CADR's & No. of patients \\
\hline \multirow{11}{*}{$\begin{array}{l}\text { Antimicrobial agent/ } \\
\text { antibiotics (42.5) }\end{array}$} & Ofloxacin (10) & Fixed Drug eruption & 8 \\
\hline & Amoxicillin (2.5) & Fixed Drug eruption & 2 \\
\hline & Levofloxacin (2.5) & Fixed Drug eruption & 2 \\
\hline & Ampicillin (2.5) & Maculopapular eruption & 2 \\
\hline & Vancomycin (2.5) & Urticaria + Angioedema & 2 \\
\hline & Amoxicillin (2.5) & Urticaria & 2 \\
\hline & Sulfamethoxazole (10) & Fixed Drug eruption & 8 \\
\hline & Sulbactam (2.5) & Maculopapular eruption & 2 \\
\hline & Clofazimine (2.5) & Hyperpigmentation & 2 \\
\hline & Dapsone (2.5) & Steven Johnsons Syndrome & 2 \\
\hline & Metronidazole (2.5) & Fixed Drug eruption & 2 \\
\hline \multirow{2}{*}{ NSIADs (20) } & Ibuprofen $(2.5)$ & Angioedema & 2 \\
\hline & Nimesulide (2.5) & Fixed Drug eruption & 2 \\
\hline
\end{tabular}




\begin{tabular}{|c|c|c|c|}
\hline Group (\%) & Drugs & CADR's & No. of patients \\
\hline & Ibuprofen (2.5) & Fixed Drug eruption & 2 \\
\hline & Nimesulide (2.5) & Hyperpigmentation & 2 \\
\hline & Ibuprofen (2.5) & Maculopapular eruption & 2 \\
\hline & Ibuprofen (2.5) & Urticaria & 2 \\
\hline & Diclofenac (2.5) & Urticaria & 2 \\
\hline \multirow{6}{*}{ Antiepileptic (17.5) } & Phenytoin (2.5) & Fixed Drug eruption & 2 \\
\hline & Phenytoin (5) & Maculopapular eruption & 4 \\
\hline & Phenobarbitone (2.5) & Maculopapular eruption & 2 \\
\hline & Carbamazepine (2.5) & Maculopapular eruption & 2 \\
\hline & Phenytoin (2.5) & Steven Johnsons Syndrome & 2 \\
\hline & Carbamazepine (2.5) & Urticaria & 2 \\
\hline \multirow{2}{*}{ Antihypertensive (5) } & Losartan (2.5) & Urticaria + Angioedema & 2 \\
\hline & Lisinopril (2.5) & Urticaria & 2 \\
\hline \multirow{3}{*}{ Analgesic \& Antipyretic (7.5) } & Paracetamol (2.5) & Angioedema & 2 \\
\hline & Paracetamol (2.5) & Fixed Drug eruption & 2 \\
\hline & Aspirin (2.5) & Urticaria & 2 \\
\hline
\end{tabular}

Table 5 shows that most of the study subjects were in probable causality assessment of the Naranjo's scale i.e. $82.5 \%$ followed by definite in $12.5 \%$ and possible in $5 \%$.

Table 6 shows that most of the CADR's were in probable causality assessment of Naranjo's scale. Fixed drug eruption was the most common CADR's i.e. $42.5 \%$ out of which $82.35 \%$ belongs to probable group.

Table 7 shows that most of the ADR were caused by antimicrobial agent i.e. $42.5 \%$ followed by NSAIDs (20\%). A simple drug can give rise to more than one morphological pattern of cutaneous ADRs. In above table it shows that ibuprofen (10), ofloxacin (10), sulfamethoxazole (10) are the commonest individual drug incriminated in CADRS.

\section{DISCUSSION}

Any drug can cause adverse drug reaction. Cutaneous reactions are the most common manifestation of adverse drug reaction. ${ }^{7}$ Cutaneous ADRs can be caused by a wide range of drug. The spectrum of cutaneous manifestation may range may from simple maculopapular rashes to life threatening Toxic epidermal necrolysis (TEN). A drug can produce different morphological types of reactions and as well as different classes of drug can produce similar pattern of drug reaction. Some CADRs can result in serious morbidity and even death. ${ }^{8}$

In this study the frequency of CADRs was maximum in patient with age group of $41-50$ years $(32.50 \%)$ followed by $31-40$ years $(25 \%)$. This is in accordance with the study by James et al. ${ }^{9}$ However, one study done in North India, the common age affected was found to be 20-29 years. ${ }^{10}$ This difference may be related to regional variation in health care seeking behavior. In our study male experienced slightly a greater number of CADRs as compared to female (male: female ratio of 11.85:8.5).
In present study the onset of reaction in majority of study subject (42.50\%) was between 24 hours to 1 week followed by $<24$ hours in $40 \%$ of subjects. This, is in concordance with study done by Hotchandani et al gradual progression of symptoms was seen in majority of subject $(60 \%) .{ }^{11}$ Total duration of reaction was $<1$ week in majority of subject (72.50\%). Associated symptoms in the form of itching, burning, fever and combination of these symptoms was seen in $(57.50 \%)$ of study subjects.

For the purpose of diagnosis Naranjo's algorithm has been used which in a simple questionnaire which can be easily used at bed side for causality assessment of ADRs. Other causality assessment scales was used in previous studies being World Health Organization (WHO) protocol. ${ }^{12}$ According to Naranjo's algorithm 66 cases $(82.5 \%)$ had probable, 10 cases $(12.5 \%)$ had definite and 4 cases $(5 \%)$ possible causal relationship with the drug in the present study.

CADR's can assume various morphological patterns. In the present study fixed drug eruption was the most common CADR's (40\%) followed by maculo-papular eruption (20\%). A large study was done in Italy also reported that anti-microbial agents (AMAs) were the most common cause of CADR's. ${ }^{13}$ Previous study in India also has shown that AMA's are the major causative agents for CADR's. ${ }^{14}$

Among the AMA's cutaneous ADR's were commonly associated with fluoroquinolone group of antimicrobials followed by sulfamethoxazole and penicillin. In a study done by Panneerselvam et al among the antimicrobials fluoroquinolones, the third-generation cephalosporins and NSAIDs contributed to the maximum number of CADRs. ${ }^{15}$ Also Clarkson et al showed that cotrimoxazole was commonly incriminated AMA which is in accordance with our study. ${ }^{16}$ In oner other study it was seen that CADRs was more common with amoxicillin-clavulanic acid (18.95\%), ciprofloxacin (14.91\%), amoxicillin (14.11\%) 
and others which is in accordance with our study. ${ }^{17}$ The most common group of drugs associated with fixed drug eruption were AMAs ofloxacin, sulfamethoxazole. This is in conformity with studies done in India reports of sulfonamide being emerging as the most common cause of Fixed drug eruptions (FDE). ${ }^{18}$

NSAIDs were associated with majority of drug induced urticaria. This is similar with the findings of study in India and U.K. ${ }^{19,20}$ The reaction time varied from 2 days to one week. Most of the reaction was associated with anticonvulsant like phenytoin. Similar finding has been reported by a study done in North India. ${ }^{10}$ Complication were seen in patient with SJS and included ocular involvement and oral candidiasis. Thus, in this study a wide clinical spectrum of cutaneous ADR's ranging from FDE maculopapular eruption to serious SJS was observed.

\section{CONCLUSION}

In this study fixed drug eruption was the most common CADRs and most of these drug eruptions were caused by AMA's. Among the AMAs cutaneous ADRs were commonly seen with sulpha group. Most seriously ADRs were associated with anticonvulsants. The study provided baseline information about the prevalence of CADRs and their morphological distribution amongst different age group, gender and causative drugs emphasizes the need for most extensive ADR monitoring in the hospital and will be useful in framing policies towards rational use of drugs.

\section{Funding: No funding sources}

Conflict of interest: None declared

Ethical approval: The study was approved by the Institutional Ethics Committee

\section{REFERENCES}

1. Svensson CK, Cowen EW, Gaspari A. Cutaneous drug reations. Pharmacological reviews. 2002;53(3):35779.

2. Sharma VK, Sethuraman G. Adverse cutaneous reactions to drugs: an overview. J postgrad Med. 1996;42:15-22.

3. Aquier DA, Mockenhaupt M, Naidi L. Correlation between clinical patterns and causes of erythema multiform major; Stevens-Johnson syndrome and toxic epidermal necrolysis results of an international prospective study. Arch Dermatol. 2002;138:1019-24

4. Billimoria FE, Shah BJ. Textbook and atlas of dermatology: Drug reaction. 3rd Edition. Bhalani, Mumbai. 2008;16:33-68.

5. Batson PJ. Drug induced chromosomal change; Adverse drug Reaction Bull. 1972;31:72-7.

6. Naranjo CA, Busto V, Sellers EM. A method for estimating the probability of adverse drug reactions. Clin pharmacol Ther. 1981;30(2):239-45.
7. Sushma M, Noel MV, Ritika MC, James J, Guido S. Cutaneous adverse drug reaction: a 9-year study from south Indian hospital. Pharmacoepidemiol Drug safety. 2005;14(5):67-70.

8. Porteous DM, Berger TG. Severe cutaneous drug reactions (Steven Johnson syndrome and toxic epidermal necrolysis) in human immunodeficiency virus infection. Arch Dermatol. 1991;127:740-1.

9. James J, Sushma M, Guido S, Elizabeth J. Cutaneous adverse drug reactions in south Indian tertiary center. Indian J Dermatol. 2005;50(1):17-21.

10. Nandha R, Gupta A, Hashmi A. Cutaneous adverse drug reactions in a tertiary care teaching hospital: A North Indian Perspective. Int J App Basic Med Res. 2011;1:50-3.

11. Hotchandani SC, Bhatt JD, Shah MK. A prospective analysis of drug-induced cutaneous reactions reported in patients at tertiary care hospital. Indian J pharmacol. 2010; 42(2)116:19.

12. Idsoe O, Guthe T, Willcox RR. Nature and extent of penicillin side reaction, with particular reference to fatalities from anaphylactic shock. Bull WHO. 1968;38:159-88.

13. Luigi $\mathrm{N}$, Anita $\mathrm{Cu}$, Mauro V. Cutaneous reactions to drugs. An analysis of spontaneous reports in four Italian regions. Dr J Clin Pharmacol. 1999;48:839-46.

14. Crib AE, Lee BL, Trepanier LA. Adverse reactions to sulfonamide and sulfonamide-trimethoprim antimicrobials: clinical syndromes and pathogenesis. Adverse Drug React Toxical Rev. 1996;15:9-50.

15. Panneerselvam N, Kadhirvelu P, Somasundaram R, Jayaprakash S. A study on cutaneous adverse drug reactions reported in a tertiary care hospital, kanchipuram. sian J Pharm Clin Res. 2020;13(1):747.

16. Clarkson A, Choonara I. Surveillance for fatal suspected adverse drug reaction in the UK. Archives of disease in childhood. 2002;87:462-6.

17. Badar V, Parulekar VV, Garate P. A surveillance study of cutaneous adverse drug reactions in a tertiary care teaching hospital in India. Int J Basic Clin Pharmacol. 2018;7:2439-46.

18. Dhar S, Sharma VK. Fixed drug eruption due to ciprofloxacin. Br J Dermatol. 1996;134:156-8.

19. Soter N. A. Acute and chronic urticaria and angiodema. J Am Acad dermatol.1991;25:155-65.

20. Eunice KH. Grattan: Drug-induced urticaria. Expert opinion on drug Safety. 2004:3(5):471-84.

Cite this article as: Shende TR, Siddqui RA. A clinical study of morphological patterns of cutaneous adverse drug reaction and its causality assessment in tertiary care hospital of central India. Int J Basic Clin Pharmacol 2020;9:1528-32. 